\title{
Role of hystero-laparoscopy with chromopertubation as a diagnostic cum therapeutic tool in evaluation and treatment of female infertility
}

\author{
Kavitha G, Renukadevi B \\ Correspondence: Dr. Kavitha G, MS (OBG), Associate professor, OBG Department, \\ Velammal medical college and research center, Madurai, Tamilnadu, India; Email - \\ kavithag_17@yahoo.com \\ Distributed under Attribution - Non Commercial - Share Alike 4.0 International (CC BY-NC-SA 4.0)
}

\begin{abstract}
Objectives: The purpose of this study is to assess the role of hystero-laparoscopy in diagnosis and treatment of the possible causes of female infertility and also to plan further management protocol for the infertile couple. Methods: This was a retrospective study conducted on 125 infertile patients who underwent hysterolaparoscopy with chromopertubation during the years 2013-2018. Data of the identified patients were collected from their case records. Intra-operative laparoscopy, hysteroscopy and chromopertubation findings were recorded and statistically analysed. Results: One hundred twenty five (125) infertile women underwent hysterolaparoscopy with chromopertubation during the study period. Hundred four $(83.2 \%)$ patients had primary infertility while $21(16.8 \%)$ patients had secondary infertility. Seventy two $(57.6 \%)$ patients had abnormal laparoscopic findings. Most common abnormal laparoscopic finding was endometriosis in 32(25.60\%) patients. Commonest hysteroscopic abnormality was uterine anomaly in $13(10.5 \%)$ patients. On chromopertubation tubal block was found in $16(13.8 \%)$ patients. Of the 125 infertile patients therapeutic procedures were performed in 73 patients. Commonly performed procedures were adhesiolysis (21.91\%), PCO drilling (20.54\%) and ovarian cystectomy (19.17\%). Twelve patients with bilateral tubal disease were advised to undergo ART, 39 patients were advised natural cycle and 74 patients planned for ovulation induction with or without IUI. Conclusion: The commonest possible cause of infertility identified by our study was endometriosis. Hystero-laparoscopy with chromopertubation is definitely very useful not only in diagnosis and treatment of pelvic pathology, but also to plan whether the couple need ART or not.
\end{abstract}

Keywords: Infertility, hystero-laparoscopy, chromopertubation, ovulation induction, assisted reproductive technology (ART).

According to WHO, positive reproductive health of a woman is a state of physical, mental and social wellbeing and not merely absence of diseases in reproductive system and its functions and process. The society and its culture have a major role in psychological impacts on infertile couple. It puts high values on couples bearing children and is less supportive to those who cannot fulfil this expectation. Infertility varies across regions of the world

Received: $24^{\text {th }}$ January 2019. Accepted: $22^{\text {th }}$ March 2019.

Kavitha G, Renukadevi B. Role of hystero-laparoscopy with chromopertubation as a diagnostic cum therapeutic tool in evaluation and treatment of female infertility. The New Indian Journal of OBGYN. 2019; 6(1): 15-9 
and is estimated to affect 8 to 12 per cent of couples worldwide ${ }^{1,2}$. The prevalence of primary infertility in India is estimated to be between 3.9 and 16.8 percent by the WHO. The diagnostic evaluation for infertility is usually started when women fail to achieve a successful pregnancy after 12 months or more of regular unprotected intercourse. Women older than age 35 years needs to be evaluated earlier, after 6 months of failed efforts to conceive and this should also be done in patients based on medical history and physical findings ${ }^{3}$, including history of oligo or amenorrhea, known or suspected pelvic pathology, and known or suspected male subfertility.

The aetiology of female infertility can be broken down into ovulation disorders, uterine abnormalities, tubal obstruction, peritoneal factors and cervical factors. The investigations done for infertility are usually a standardized one, a good detailed history and thorough examination allows one to individualize the investigation process. The choice of investigations mainly depends on the patient's age, duration of infertility, response to previous treatment. The choice often lies between a diagnostic approach favouring laparoscopic evaluation and a therapeutic approach favouring the use of assisted reproductive techniques. Laparoscopy with chromopertubation is the 'gold standard' method of endometriosis and tubal assessment. Hysteroscopy is 'gold standard' method of assessing the uterine cavity. The purpose of this study is to assess the role of hysterolaparoscopy in diagnosis and treatment of the possible causes of female infertility and also to plan further management protocol for the infertile couple.

\section{Methodology}

This is a retrospective study conducted on infertile patients who underwent hystero-laparoscopy with chromopertubation for evaluation of infertility at Velammal Medical College Hospital and Research Institute, Madurai, Tamilnadu, India from the year June 2013 to June 2018. Infertility is defined as inability of the couple to achieve pregnancy after 1 year of unprotected and regular intercourse. Primary infertility was defined as couple those who had never conceived before, while secondary infertility was defined as patients who had at least one prior conception, irrespective of the outcome.

Inclusion criteria: Patients between 19 and 40 years of age with either primary or secondary infertility of more than one year duration who underwent diagnostic hysteron-laparoscopy.

Exclusion criteria: 1) Patients with active pelvic infections, 2) Couples with male factor infertility, 3) Patients with contraindications for laparoscopy (preexisting severe medical disorders).

Hystero-laparoscopy with chromopertubation was performed in the immediate post menstrual phase by a standardised technique. Details of the study patients were collected from the case records in the medical record section. Details collected include age, duration of infertility, type of infertility, previous treatment for infertility (OI, IUI, IVF), BMI, clinical examination findings, ultrasound, SSG/HSG findings, laparoscopic, hysteroscopy and chromopertubation findings. While performing hystero-laparoscopy whenever there was a pathological finding and if it was indicated, therapeutic procedures were done.

Data were collected on a proforma, and analysed on SPSS package for windows version 10. Frequencies were calculated for laparoscopic, hysteroscopic and chromopertubation findings of primary and secondary infertility.

\section{Results}

We studied 125 infertile patients, out of which 104 patients $(83.2 \%)$ presented with primary infertility and 21 Table 1: Types of Infertility

\begin{tabular}{ll}
\hline Types & Number (\%) \\
\hline Primary & $104(83.20 \%)$ \\
Secondary & $21(16.80 \%)$ \\
Total & 125 \\
\hline
\end{tabular}

patients (16.8\%) presented with secondary infertility (Table 1). The overall age at presentation was 21-30 years, which are 21-25 years in primary infertility and 26-

Table 2: Age distribution

\begin{tabular}{lll}
\hline $\begin{array}{l}\text { Age } \\
\text { (years) }\end{array}$ & $\begin{array}{l}\text { Primary } \\
\text { infertility }\end{array}$ & $\begin{array}{l}\text { Secondary } \\
\text { infertility }\end{array}$ \\
\hline & Number (\%) & Number (\%) \\
\cline { 2 - 3 }$<20$ & $2(1.92 \%)$ & - \\
$21-25$ & $40(38.46 \%)$ & $2(9.52 \%)$ \\
$26-30$ & $25(24.03 \%)$ & $12(57.14 \%)$ \\
$31-35$ & $14(13.46 \%)$ & $5(23.80 \%)$ \\
$>36$ & $23(22.11 \%)$ & $2(9.52 \%)$ \\
\hline
\end{tabular}

30 years in secondary infertility (Table 2). Majority of patients had an average married life of 1-5 years in primary group and 6-10 years in secondary group in this study (Table 3). 
Table 3: Duration of infertility

\begin{tabular}{lll}
\hline $\begin{array}{l}\text { Duration in } \\
\text { years }\end{array}$ & $\begin{array}{l}\text { Primary } \\
\text { infertility }\end{array}$ & $\begin{array}{l}\text { Secondary } \\
\text { infertility }\end{array}$ \\
\hline & Number (\%) & Number (\%) \\
\cline { 2 - 3 } $1-5$ & $46(44.23 \%)$ & $7(33.33 \%)$ \\
$6-10$ & $40(38.46 \%)$ & $13(61.90 \%)$ \\
$11-15$ & $14(13.46 \%)$ & $1(4.76 \%)$ \\
$>16$ & $4(3.84 \%)$ & - \\
\hline
\end{tabular}

The different causes of infertility in the study group are shown in (Table 4). Laparoscopy revealed normal

Table 4: Laparoscopic findings

\begin{tabular}{llll}
\hline Findings & Primary & Secondary & Total \\
\hline & $\mathbf{( N = 1 0 4 ) ( \% )}$ & $\mathbf{( N = 2 1 ) ( \% )}$ & $\mathbf{( N = 1 2 5 ) ( \% )}$ \\
\cline { 2 - 4 } Fibroid uterus & $16(15.38)$ & $1(4.76)$ & $17(13.6)$ \\
PCO & $11(10.57)$ & $5(23.80)$ & $16(12.80)$ \\
Endometriosis & $27(25.96)$ & $5(23.80)$ & $32(25.60)$ \\
Simple ovarian cyst & $1(0.96)$ & $1(4.76)$ & $2(1.6)$ \\
Uterine anomaly & $4(3.84)$ & $1(4.76)$ & $5(4.00)$ \\
Normal & $45(43.26)$ & $8(38.09)$ & $53(42.40)$ \\
Grand total & $104(100)$ & $21(100)$ & $125(100)$ \\
\hline
\end{tabular}

findings in 53(42.4\%) patients, of which 45(43.26\%) out of 104 patients with primary infertility and $8(38.09 \%)$ of

Table 5: Hysteroscopy findings

\begin{tabular}{llll}
\hline Findings & Primary & Secondary & Total \\
\hline & $(\mathbf{n = 1 0 4 )}(\mathbf{\%})$ & $\mathbf{( n = 2 1 ) ( \% )}$ & $\mathbf{( n = 1 2 5 ) ( \% )}$ \\
\cline { 2 - 4 } $\begin{array}{l}\text { Normal } \\
\text { Intrauterine }\end{array}$ & $31(77.88)$ & $20(95.23)$ & $101(80.80)$ \\
adhesions & & - & $3(2.40)$ \\
Endometrial polyp & $5(4.80)$ & - & $5(4.00)$ \\
Uterine anomaly & $13(12.5)$ & - & $13(10.40)$ \\
Cervical stenosis & $1(0.96)$ & $1(4.76)$ & $2(1.60)$ \\
Not done & $1(0.96)$ & - & $1(0.80)$ \\
Grand total & $104(100)$ & $21(100)$ & $125(100)$ \\
\hline
\end{tabular}

Table 6: Chromopertubation findings

\begin{tabular}{llll}
\hline Types & Primary & Secondary & Total \\
\hline & $(\mathbf{n = 1 0 4 )}(\mathbf{\%})$ & $\mathbf{( n = 2 1 ) ( \% )}$ & $\mathbf{( n = 1 2 5 ) ( \% )}$ \\
\cline { 2 - 4 } Normal & $86(82.69)$ & $15(61.90)$ & $99(79.20)$ \\
Unilateral block & $2(1.92)$ & $5(23.80)$ & $7(5.6)$ \\
Bilateral block & $9(8.65)$ & - & $9(7.2)$ \\
Unilateral delayed spill & $3(2.88)$ & $1(4.76)$ & $4(3.2)$ \\
Bilateral delayed spill & $3(2.88)$ & - & $3(2.4)$ \\
Not done & $1(0.96)$ & - & $1(0.8)$ \\
Grand total & $104(100)$ & $21(100)$ & $125(100)$ \\
\hline
\end{tabular}

21 patients with secondary infertility. Abnormal findings were present in $72(57.6 \%)$ patients, of which $59(56.73 \%)$ in primary and $13(61.9 \%)$ in secondary infertility. The most common finding observed by laparoscopy in primary group was endometriosis in $27(25.96 \%)$ patients, fibroid uterus in $16(15.38 \%)$ patients, followed by polycystic ovaries in $11(10.57 \%)$ patients. While in secondary $5(23.8 \%)$ patients had endometriosis, 5 $(23.8 \%)$ patients had polycystic ovaries and $1(4.76 \%)$ patient had fibroid uterus.

In our study the commonest hysteroscopic abnormality in primary infertility was a uterine anomaly in $13(12.5 \%)$ patients followed by endometrial polyp in $5(4.80 \%)$ patients and intrauterine adhesions in $3(0.96 \%)$ patients. In the secondary infertility group only one (4.70\%) patient had cervical stenosis, rest of the patients had normal uterine cavity (Table 5).

In the primary infertility group chromopertubation was performed in 103 patients, 11(10.61\%) patients had tubal block, out of which $9(8.65 \%)$ patients had bilateral tubal block, 2(1.96\%) patients had unilateral tubal block and $6(5.76 \%)$ patients had delayed spill in one of the tube. In the secondary infertility group out of 21 patients, 5(23.8\%) patients had unilateral block and $1(4.76 \%)$ patients had delayed spill in the tubes (Table 6).

Depending on the pathology found on hysterolaparoscopy, various therapeutic procedures were performed, totally around 73 procedures were performed, 55 procedures in primary infertility group and 18 procedures in secondary infertility group, the most commonly performed procedures were adhesiolysis in $21.91 \%$ patients, PCO drilling in $20.54 \%$ patients and ovarian cystectomy in $19.17 \%$ patients. The commonly performed procedure in the primary infertility group, was adhesiolysis in $14(25.45 \%)$ patients, PCO drilling in $10(18.18 \%)$ patients, ovarian cystectomy in $10(18.18 \%)$ patients, proximal tubal cannulation in $8(14.54 \%)$ patients, myomectomy in 5(9.09\%) patients, septal resection in $5(9.09 \%)$ patients, hysteroscopic polypectomy in $3(5.45 \%)$ patients. In secondary infertility myomectomy was performed in $5(27.77 \%)$ patients and PCO drilling in $5(27.77 \%)$ patients, ovarian cystectomy in $4(22.22 \%)$ patients, proximal tubal cannulation in $2(11.11 \%)$ patients and adhesiolysis in $2(11.11 \%)$ patients (Table 7). Twelve patients with bilateral tubal disease were advised to undergo ART, 39 patients advised natural 
Table 7: Fertility enhancing therapeutic procedure

\begin{tabular}{|c|c|}
\hline \multicolumn{2}{|l|}{ Procedures } \\
\hline \multicolumn{2}{|c|}{$\begin{array}{l}\text { Proximal tubal canulation } \\
\text { Ovarian Cystectomy } \\
\text { Myomectomy } \\
\text { Adhesiolysis } \\
\text { PCO drilling } \\
\text { Hysteroscopic polypectomy } \\
\text { Septal resection } \\
\text { Grand total }\end{array}$} \\
\hline \multicolumn{2}{|c|}{$\begin{array}{l}\text { cycle and } 74 \text { patients were } \mathrm{p} \\
\text { IUI (Table } 8 \text { ). }\end{array}$} \\
\hline \multicolumn{2}{|c|}{ Table 8: Treatment plan } \\
\hline Types & Number \\
\hline Natural cycle & 39 \\
\hline OI (+/-)IUI & 74 \\
\hline IVF/ICSI & 12 \\
\hline Total & 125 \\
\hline
\end{tabular}

\begin{tabular}{lll} 
Primary & Secondary & Total \\
\hline$(\mathbf{n}=\mathbf{1 0 4})(\mathbf{\%})$ & $(\mathbf{n = 2 1})(\mathbf{\%})$ & $(\mathbf{n = 1 2 5})(\%)$ \\
\hline $8(14.54)$ & $2(11.11)$ & $10(13.69)$ \\
$10(18.18)$ & $4(22.22)$ & $14(19.17)$ \\
$5(9.09)$ & $5(27.77)$ & $10(13.69)$ \\
$14(25.45)$ & $2(11.11)$ & $16(21.91)$ \\
$10(18.18)$ & $5(27.77)$ & $15(20.54)$ \\
$3(5.45)$ & - & $3(4.10)$ \\
$5(9.09)$ & - & $5(6.84)$ \\
$55(75.34)$ & $18(24.65)$ & $73(100)$ \\
\hline
\end{tabular}

The most common pelvic pathology in our study was endometriosis in both primary and secondary infertility group which is comparable with study by Meuleman $\mathrm{C}$ et al ${ }^{9}$, which also had a high incidence of endometriosis (47\%) suggesting laparoscopy and hysteroscopy to all couples with unexplained infertility.

In our study the $91(80 \%)$ patients out of 125 patients had normal findings on hysteroscopy comparable to a retrospective study by Bhandari S et al, where 152(76\%) patients had normal findings. In our study hysteroscopic findings were more common in primary infertility group as opposed to study by Bhandari $\mathrm{S}$ et al ${ }^{7}$. The most common hysteroscopic abnormality in primary infertility was uterine anomaly followed by endometrial polyp. The association of uterine anomalies to infertility is still debatable, but there are sufficient evidences to prove that endometrial polypectomy improves fertility.

In our present study, the frequency of abnormal tubal spill on chromopertubation was more in secondary group with $6(28.57 \%)$ patients compared to primary group with $17(16.33 \%)$ patients similar to that found in a prospective study by Chaitra Krishna et al ${ }^{8}$ where $33.3 \%$ patients in secondary and $28.5 \%$ patients in primary infertility had abnormal tubal spill. Hystero-laparoscopy with chromopertubation is definitely superior in diagnosis of various kinds of tubal pathologies. A total of 73 therapeutic procedures were performed in both primary and secondary infertile patients, the most commonly performed procedures where adhesiolysis in $21.91 \%$ patients, PCO drilling in $20.54 \%$ patients, ovarian cystectomy in $19.17 \%$ patients, proximal tubal cannulation, septal resection and polypectomy comparable with a prospective study conducted in Ludhiana by Puri $\mathrm{S}$ et $\mathrm{al}^{10}$, were adhesiolysis in $22 \%$, ovarian drilling in $22 \%$, ovarian cystectomy in $4 \%$. Always be equipped to perform a therapeutic procedure when you are planning a diagnostic hystero-laparoscopy. Twelve patients with bilateral tubal disease were advised to undergo ART, 39 patients advised natural cycle and 74 patients planned for OI with or without IUI. 


\section{Conclusion}

Endometriosis was the commonest cause in both primary and secondary infertility. Hystero-laparoscopy with chromopertubation is a very important procedure in the diagnosis of pelvic pathology in female infertility, which at the same sitting offers an opportunity for the treatment of the diagnosed pathology in the uterus, tubes, ovaries, or peritoneum, and thus decreasing the need for a repeat procedure and also allows to plan for further management. It gives a clear idea about, what treatment the couple has to be offered like natural cycle, OI, OI with IUI or ART. It helps in reducing the number of patients who actually need ART.

\section{Conflict of interest: None. Disclaimer: Nil.}

\section{References}

1.Sciarra J. Infertility: an international health problem. Int J Gynaecol Obstet. 1994; 46:155-63. [PubMed]

2.Looking back, looking forward: a profile of sexual and reproductive health in India. New Delhi: Population Council; 2004. pp 67-72.

3.Infecundity, infertility, and childlessness in developing countries. DHS Comparative Reports No 9. Calverton, Maryland, USA: ORC Macro and the World Health Organization; 2004. (World Health Organization).

4.Boivin J, Bunting L, Collins JA, Nygren KG. International estimates of infertility prevalence and treatment-seeking: potential need and demand for infertility medical care. Hum Reprod. 2007 Jun; 22(6):1506-12.

5.Qurat-ul-Ain W, Ara R, Dangroo SA, Beig M. Diagnostic Laparoscopy in the Evaluation of Female Factors in Infertility in Kashmir Valley. Int J Women's Health Reprod. 2014; 2(2): 48-57.

6.Kotdawala P, Kotdawala S. Role of laparoscopy before Intrauterine insemination. In: Mukherjee GG, Chakravarty BN, editors. Intrauterine Insemination. New Delhi: Jaypee Brothers Medical Publication Pvt Ltd; 2012. p.45.

7.Bhandari S, Singh A, Agrawal P, Ganguli I. Findings in diagnostic laparoscopy in patients with unexplained infertility. Fertil Sci Res. 2015; 2(1): 29-33.

8.Chaitra K, Prathima S, Chandraiah S, GS Anitha. Laparoscopy as a diagnostic tool in evaluation of female factors in infertility. Int $\mathrm{J}$ Reprod Contracept Obstet Gynecol. 2017 Mar; 6(3): 864-7.

9.Meuleman C, Vandenabeele B, Fieuws S, Spiessens C, Timmerman D, D'Hooghe T. High prevalence of endometriosis in infertile women with normal ovulation and normospermic partners. Fertil Steril. 2009 Jul; 92(1): 68-74.

10.Puri S, Jain D, Puri S, Kaushal S, Deol SK. Laparohysteroscopy in female infertility - A diagnostic cum therapeutic tool in Indian setting. Int J App Basic Med Res. 2015; 5(1): 46-8.

Kavitha $\mathbf{G}^{1}$, Renukadevi $\mathbf{B}^{2}$

${ }^{1}$ Associate Professor; ${ }^{2}$ Associate Professor, Department of Obstetrics and Gynaecology, Velammal medical college, Madurai, Tamilnadu, India. 